\title{
Estimating sex using discriminant analysis of mandibular measurements from a modern Greek sample
}

\author{
Andreas Bertsatos, Konstantina Athanasopoulou and Maria-Eleni Chovalopoulou* (i)
}

\begin{abstract}
Background: Sex determination is an integral and fundamental step in biological profile construction. The mandible, which holds many dimorphic traits, can be useful for sex estimation in the forensic context. However, reliable sex estimation usually relies on population-specific mandibular morphometric criteria. To date, no such criteria are available for the modern Greek population, and the present study aims to fill this lack of data by identifying the most sexually dimorphic mandibular traits on a modern Greek population sample and reporting the discriminant functions that can most effectively be used for estimating sex.
\end{abstract}

Materials and methods: For the purposes of this research, the 3D models of 194 adult mandibles (105 males and 89 females) from the Athens skeletal reference collection were used. A battery of 20 linear and 3 angular measurements was calculated from the 3D coordinates of anatomical landmarks positioned on the respective models and was analyzed by means of ANOVA and discriminant function analysis to investigate the expression of sexual dimorphism.

Results: The coronoid height, the ramus height, and the maximum mandibular length are the most sexually dimorphic metric traits of the mandible, while the produced sex discriminant functions yielded cross-validated classification accuracy up to $85.7 \%$ for the Greek sample. Furthermore, most of the examined combinations of measurements exhibited the same sex discriminant capacity between different reference samples, despite their respective discriminant functions being population specific.

Conclusions: Our findings indicate that the produced sex discriminant functions can be effectively used for sex determination in forensic casework and to verify the population specificity of these functions but also suggest that the expression of sexual dimorphism in the mandible shares certain features across different populations.

Keywords: Sex determination, Discriminant function analysis, Mandibular measurements, Greek population

\section{Background}

It is well established that the estimation of various biological profile parameters, such as age at death and stature, is affected by sex (Bidmos et al. 2010; Krishan et al. 2016). Therefore, sex determination is an integral and fundamental step in biological profile construction from skeletal remains (Lin et al. 2014;

\footnotetext{
* Correspondence: marilenachov@biol.uoa.gr

Department of Animal and Human Physiology, Faculty of Biology, School of Sciences, National and Kapodistrian University of Athens, Panepistimiopolis, GR 15701 Athens, Greece
}

Lopez-Capp et al. 2017). Although sex can be determined by forensic anthropologists with an accuracy of $90-100 \%$ when the entire skeleton is available (Byers 2016), in cases where the skeleton is incomplete or fragmented, sex determination can be more difficult (Passalacqua et al. 2013). Hence, the need of reliable sex discriminatory methods based on individual parts of the skeleton is evident.

Most human bones exhibit sexual dimorphism, while the pelvis is the most reliable sex estimator, followed by the skull and the humerus (France 1998). However, when the pelvis and the skull are fragmented or missing, the mandible can be useful for estimating sex in a 
forensic context, since it is often well preserved and it holds many dimorphic traits (Franklin et al. 2007; Franklin et al. 2008; Saini et al. 2011). The mandible exhibits sexual dimorphism from an early stage of life (Kano et al. 2015). More specifically, earlier studies have shown that the expression of sexual dimorphism can be detected from as early as 5 months old (Schutkowski 1993; Loth and Henneberg 2001; Scheuer 2002). Nevertheless, mandibular sexual dimorphism is reduced during childhood (between the ages of 4 and 14), while it becomes again most prominent during adulthood (Coquerelle et al. 2011). Furthermore, it has been demonstrated that the sex-related morphological characteristics exhibit both inter- and intra-population variability, which is influenced by a range of factors including genetics, nutrition, secular change, growth, and morbidity as well as other general environmental factors (Ubelaker and DeGaglia 2017).

Various sex discriminating morphological and morphometric traits of the mandible have been described in the literature, such as the "mandibular ramus flexure" or the "ramus length," respectively (Hu et al. 2006; Dong et al. 2015; Sharma et al. 2016). However, morphometric analyses, as opposed to qualitative sex discriminant methods, are more commonly used due to its inherent objectivity, accuracy, reproducibility, and lower level of inter- and intra-observer errors (Saini et al. 2011; Carvalho et al. 2013; Sharma et al. 2016).

Linear discriminant analysis is a simple-to-implement yet accurate classifier for normally distributed datasets (Dixon and Brereton 2009). Hence, it is commonly used in forensic applications for developing sex discriminant functions (Franklin et al. 2005; Dayal et al. 2008; Ogawa et al. 2013). Over the years, numerous sex discriminant functions based on mandibular measurements have been reported for various populations (Giles 1964; Steyn and İșcan 1998; Franklin et al. 2008; Saini et al. 2011; Lin et al. 2014; Dong et al. 2015). Nevertheless, the subtlety of metric assessments renders any derived sex discriminant function highly population specific as well as sensitive to secular trends (Dayal et al. 2008). Hence, their sex discriminating capacity usually diminishes when applied on samples different from the reference population. To date, no such study has been conducted on a modern Greek population sample and the aim of the present study was to fill this gap by identifying those mandibular morphometric traits that can be most effectively used in sex assessment. Additionally, this study investigated whether and to what extent discriminant functions derived from different population samples produce reliable sex estimation on the modern Greek population sample as a means to identify possible similarities in the expression of sexual dimorphism among diverse population groups. Sex discriminant functions representative for four contemporary populations from South Africa, India, and Korea have been examined to this end.

\section{Materials and methods}

For the purposes of this research, 194 mandibles of adult Greek individuals were used. The sample consisted of 105 males and 89 females. Only individuals without any evidence of pathological deformation in the mandible and skull were selected. These individuals constitute part of the modern skeletal reference collection, also known as the Athens Collection, which is housed in the Department of Animal and Human Physiology at the National and Kapodistrian University of Athens. For each individual in the collection, sex, age at death, and cause of death as well as place and year of birth are known from death records (Eliopoulos et al. 2007). The age at death of these individuals ranges from 19 to 99 years old and their respective years of birth span from 1879 to 1965 . Previous work has shown that the Athens collection is a fairly representative reference sample of the twentieth century Greek population (Bertsatos and Chovalopoulou 2017).

\section{Data acquisition}

The mandibles were previously digitized by means of 3D photogrammetry (Photoscan Pro version 1.4, Agisoft LLC, Russia) with a cross-validated model accuracy of $0.2 \mathrm{~mm}$ between repetitive digital and caliper-based measurements used for scaling. The ongoing digital documentation of the Athens Collection aims to the preservation of the physical reference collection; hence, the 3D models were utilized in the present study. The three-dimensional coordinates of 16 landmarks (3 midline and 13 bilateral) were extracted from the respective models with MeshLab software (Cignoni et al. 2008). All landmarks used in the present study are illustrated in Fig. 1, and their selection aimed to most appropriately capture the shape of the mandible but also facilitate comparisons with specific sets of measurements used in the existing literature. Most of the landmark definitions were obtained from Franklin et al. (2008), while mental foramen and lingula mandibulae were defined by Bejdová et al. (2013). The non-standard landmarks mandibular tubercle, aMRB, $p M R B$, and prp were incorporated to facilitate specific measurements. All measurements are listed in Table 1 along with their definitions. In total, 23 measurements were used in the subsequent analysis, from which three were angular and 11 bilateral linear measurements. Bilateral measurements were calculated for both sides of each mandible.

\section{Data analysis}

Intra- and inter-observer error was estimated using absolute and relative technical error measurement (TEM) as well as reliability coefficient $\mathrm{R}$ for each measurement based on a subsample of 20 randomly chosen individuals. The expression of sexual dimorphism was identified by means of ANOVA and univariate linear 


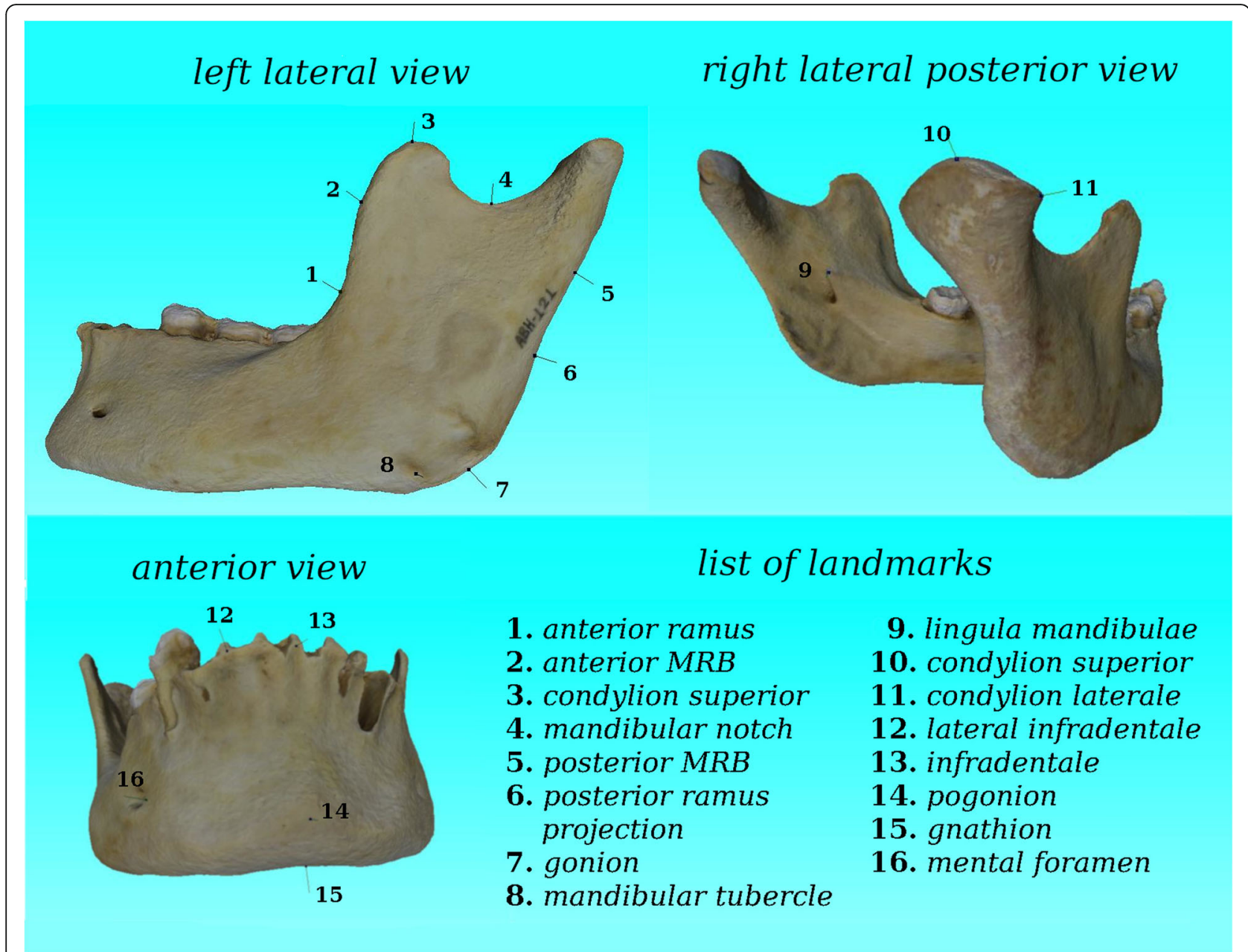

Fig. 1 Landmarks and corresponding locations

discriminant analysis on each measurement to identify those that can be most effectively used in sex assessment regarding the Greek population. Subsequently, the measurements with correct cross-validated classification in excess of $75 \%$ were analyzed by means of multivariate discriminant function analysis, using both enter and stepwise methods, to identify the combination of metric traits that can be most effectively used in sex assessment.

In order to investigate whether and to what extent the mandible-based sex discriminant functions (DFs) are population specific, previously published DFs (from different population samples) were produced from the Greek population sample for comparing their crossvalidated classification accuracy with that reported on the original population samples. More specifically, the combination of measurements of one DF from a South African Whites population sample (Steyn and İscan 1998), three DFs from a South African Blacks population sample (Franklin et al. 2008), two DFs from an Indian population sample (Saini et al. 2011), two DFs from a Korean population sample (Lin et al. 2014), and one DF from a contemporary Han Chinese population sample (Dong et al. 2015) were used for this comparison. Additionally, the classification accuracy of the previously reported DFs was also tested on the Greek sample as a measure of how their sex discriminant capacity changes when applied on a different sample than the reference population.

The evaluation of intra- and inter-observer error as well as the correct classification accuracy of applying previously published DFs on the Greek population sample were performed with the GNU Octave programming language (Eaton et al. 2016), while ANOVA and discriminant function analysis (DFA) were performed with SPSS (IBM SPSS version 23.0, Armonk, NY).

\section{Results}

Intra- and inter-observer error, by means of absolute technical error measurement (TEM), relative TEM and 
Table 1 Definitions of the measurements used in this study

\begin{tabular}{|c|c|c|}
\hline Measurement & Abbreviation & Definition $^{\mathrm{a}}$ \\
\hline Bi-condylar breadth & BicBR & The distance between right and left condylion laterale (cdl-cdl) \\
\hline Bi-gonion breadth & BigBR & The distance between right and left gonion (go-go) \\
\hline Bi-coronoid breadth & BicrBR & The distance between right and left coronion (co-co) \\
\hline Symphysis height & SyH & The distance between the gnathion and infradentale (gn-id) \\
\hline Bi-mental foramina breadth & BimfBR & The distance between right and left mental foramen ( $\mathrm{mf}-\mathrm{mf}$ ) \\
\hline Symphysis breadth & SyBR & The distance between right and left lateral infradentale (lid-lid) \\
\hline Bi-lingula breadth & BilBR & The distance between the lingula mandibulae (Im-Im) \\
\hline Mandible breadth & $\mathrm{MB}$ & The distance between right and left anterior ramus (ar-ar) \\
\hline Bi-notch breadth & BinBR & The distance between right and left mandibular notch ( $\mathrm{mn}-\mathrm{mn}$ ) \\
\hline $\begin{array}{l}\text { Angle formed by bilateral } \\
\text { gn-go lines }\end{array}$ & Agn-go & The angle formed by right gonion, gnathion and left gonion (go-gn-go) \\
\hline $\begin{array}{l}\text { Angle formed by bilateral } \\
\text { gn-co lines }\end{array}$ & Agn-co & The angle formed by right coronion, gnathion and left coronion (co-gn-co) \\
\hline $\begin{array}{l}\text { Angle formed by bilateral } \\
\text { gn-cdl lines }\end{array}$ & Agn-cdl & The angle formed by right condylion laterale, gnathion and left condylion laterale (cdl-gn-cdl) \\
\hline Ramus height ${ }^{\mathrm{b}}$ & $\mathrm{RH}$ & The distance between the condylion superior and gonion (cs-go) \\
\hline Maximum ramus height ${ }^{b}$ & $\mathrm{MRH}$ & $\begin{array}{l}\text { The distance between the most superior point on the mandibular condyle to the mandibular tubercle, or } \\
\text { most protruding point of the inferior border of the ramus (cs-mtb) }\end{array}$ \\
\hline Projective height of ramus ${ }^{b}$ & $\mathrm{PRH}$ & $\begin{array}{l}\text { Projective height of ramus between the highest point of the mandibular capitulum and lower margin of } \\
\text { the bone }(\mathrm{cs})^{c}\end{array}$ \\
\hline Coronoid height ${ }^{\mathrm{b}}$ & $\mathrm{CH}$ & Projective distance between coronion and lower wall of the bone $(\mathrm{co})^{c}$ \\
\hline Maximum ramus breadth ${ }^{b}$ & MaxRBR & $\begin{array}{l}\text { The distance between the most anterior point on the mandibular ramus and a line connecting the most } \\
\text { posterior point on the condyle and the angle of jaw (aMRB-pMRB) }\end{array}$ \\
\hline Minimum ramus breadth ${ }^{b}$ & MinRBR & Smallest anterior-posterior diameter of the ramus (ar-prp) \\
\hline Notch length ${ }^{\mathrm{b}}$ & $\mathrm{NL}$ & The distance between the coronion and condylion superior ( $\mathrm{CO}-\mathrm{CS}$ ) \\
\hline Coronion-gonion length ${ }^{b}$ & CGL & The distance between the coronion and gonion (co-go) \\
\hline Maximum body length ${ }^{b}$ & MaxBL & The distance between the gonion and pogonion (go-pg) \\
\hline Body length ${ }^{\mathrm{b}}$ & BL & The distance between the gonion and gnathion (go-gn) \\
\hline $\begin{array}{l}\text { Maximum mandible } \\
\text { length }^{b}\end{array}$ & MaxML & The distance between the condylion superior and pogonion (cs-pg) \\
\hline
\end{tabular}

${ }^{a}$ Most of landmarks definitions were obtained from Franklin et al. (2008), mental foramen and lingula mandibulae were described in Bejdová et al. (2013), while mandibular tubercle and non-standard landmarks $A M R B, p M R B$, and prp, are shown in Fig. 1

${ }^{\mathrm{b}}$ Bilateral measurements were calculated for both sides of the mandible

'The projective distance is calculated by the formula $d=(v n)$, where $n$ is the unit normal of the mandibular base plane calculated by three most inferior points of the mandibular body and $\mathrm{v}$ is a vector from any of these points to the landmark whose projective distance is being calculated

$\mathrm{R}$ coefficient, are presented in Table 2. Regarding the intra-observer error, absolute TEMs ranged within $0.16-0.43 \mathrm{~mm}$, while the values of the relative TEM ranged within $0.27-1.36 \%$. Our findings showed that the most precise measurement was BicBR and the least precise one was $\mathrm{SyH}$. The corresponding ranges concerning the inter-observer error were 0.28-0.84 $\mathrm{mm}$ and $0.46-2.77 \%$, respectively. According to the results, the most consistent measurement was MaxML (left side) while MinRBR (right side) provided the lowest consistency. $R$ coefficients showed good reliability $(R>0.95)$ for almost all measurements with the exception of six measurements (Agn-cdl, BilBR, SyBR, left-side NL, left- and right-side MinRBR), whose $R$ values ranged from 0.909 to 0.948 .
Descriptive statistics for each measurement variable are presented in Table 3, whereas Table 4 lists the respective results of ANOVA and linear discriminant analysis. Males exhibit higher mean values in all linear measurements over females and lower mean values in angular measurements with the sole exception of the angle $A g n-g o$. The univariate linear discriminant analysis revealed that only five metric traits exhibited a crossvalidated correct classification percentage over $75 \%$. These traits concerned the right-side measurements, $\mathrm{RH}, \mathrm{MRH}, \mathrm{CH}, \mathrm{CGL}$ and MaxML, which were subsequently used in multivariate DFA.

Tables 5 and 6 summarize the statistics of the discriminant function analysis for all the DFs derived from the Greek population sample for the right- and the left-side 
Table 2 Intra- and inter-observer error results

\begin{tabular}{|c|c|c|c|c|c|c|}
\hline \multirow[t]{2}{*}{ Measurement } & \multicolumn{2}{|c|}{ Intra-observer TEM } & \multirow[t]{2}{*}{$R$} & \multicolumn{2}{|c|}{ Inter-observer TEM } & \multirow[t]{2}{*}{$R$} \\
\hline & Absolute & Relative & & Absolute & Relative & \\
\hline BicBR & 0.32 & 0.27 & 0.996 & 0.61 & 0.52 & 0.987 \\
\hline BigBR & 0.33 & 0.35 & 0.997 & 0.69 & 0.72 & 0.986 \\
\hline BicrBR & 0.40 & 0.43 & 0.995 & 0.63 & 0.68 & 0.989 \\
\hline SyH & 0.39 & 1.36 & 0.982 & 0.58 & 2.03 & 0.963 \\
\hline BimfBR & 0.30 & 0.67 & 0.991 & 0.56 & 1.26 & 0.971 \\
\hline SyBR & 0.16 & 0.88 & 0.970 & 0.28 & 1.61 & 0.911 \\
\hline RH-right & 0.38 & 0.60 & 0.994 & 0.50 & 0.78 & 0.989 \\
\hline MRH-right & 0.34 & 0.50 & 0.995 & 0.70 & 1.02 & 0.978 \\
\hline PRH-right & 0.36 & 0.62 & 0.997 & 0.65 & 1.10 & 0.991 \\
\hline $\mathrm{CH}$-right & 0.37 & 0.56 & 0.997 & 0.49 & 0.75 & 0.995 \\
\hline MaxRBR-right & 0.35 & 0.82 & 0.989 & 0.66 & 1.55 & 0.967 \\
\hline MinRBR-right & 0.28 & 0.91 & 0.991 & 0.84 & 2.77 & 0.929 \\
\hline NL-right & 0.26 & 0.74 & 0.994 & 0.54 & 1.50 & 0.974 \\
\hline CGL-right & 0.39 & 0.63 & 0.997 & 0.61 & 0.99 & 0.992 \\
\hline MaxBL-right & 0.24 & 0.30 & 0.997 & 0.57 & 0.71 & 0.983 \\
\hline BL-right & 0.31 & 0.40 & 0.995 & 0.62 & 0.79 & 0.981 \\
\hline MaxML-right & 0.35 & 0.30 & 0.989 & 0.58 & 0.49 & 0.970 \\
\hline RH-left & 0.38 & 0.61 & 0.993 & 0.70 & 1.13 & 0.976 \\
\hline MRH-left & 0.25 & 0.37 & 0.998 & 0.37 & 0.55 & 0.996 \\
\hline PRH-left & 0.28 & 0.50 & 0.999 & 0.49 & 0.85 & 0.996 \\
\hline CH-left & 0.43 & 0.66 & 0.996 & 0.65 & 0.99 & 0.990 \\
\hline MaxRBR-left & 0.31 & 0.72 & 0.991 & 0.68 & 1.61 & 0.955 \\
\hline MinRBR-left & 0.39 & 1.25 & 0.963 & 0.61 & 1.97 & 0.909 \\
\hline NL-left & 0.35 & 1.03 & 0.988 & 0.75 & 2.18 & 0.943 \\
\hline CGL-left & 0.33 & 0.54 & 0.998 & 0.77 & 1.27 & 0.987 \\
\hline MaxBL-left & 0.32 & 0.39 & 0.996 & 0.71 & 0.87 & 0.979 \\
\hline BL-left & 0.27 & 0.34 & 0.997 & 0.61 & 0.76 & 0.985 \\
\hline MaxML-left & 0.34 & 0.29 & 0.988 & 0.54 & 0.46 & 0.972 \\
\hline BilBR & 0.34 & 0.43 & 0.988 & 0.70 & 0.89 & 0.946 \\
\hline MB & 0.31 & 0.37 & 0.991 & 0.59 & 0.70 & 0.969 \\
\hline BinBR & 0.35 & 0.37 & 0.993 & 0.62 & 0.66 & 0.979 \\
\hline Agn-go & 0.31 & 0.41 & 0.994 & 0.57 & 0.76 & 0.979 \\
\hline Agn-co & 0.36 & 0.63 & 0.980 & 0.57 & 1.00 & 0.954 \\
\hline Agn-cdl & 0.39 & 0.65 & 0.982 & 0.66 & 1.10 & 0.948 \\
\hline
\end{tabular}

measurements, respectively. The first nine DFs in each table concern the corresponding functions based on previously published works, whereas the latter concern the statistically permissible DFs produced by enter and stepwise methods with the most sexually dimorphic measurements found on the Greek population sample. Although no statistically significant differences were observed between the measurements of the right and left side, the corresponding equations based on the left-side measurements were produced in order to detect any differences in classification accuracy, but also for comparative consistency with previously published research.

The cross-validated classification accuracy of the examined DFs ranged from 77.1 to $85.7 \%$ with Function 7 (based on MRH and MinRBR measurements) exhibiting the lowest accuracy for both the left- and the right-side measurements and Function 4 (based on BigBR, CGL, MaxBL, and MaxML measurements) exhibiting the highest. Regarding the DFs produced by combining the most sexually dimorphic measurements from the Greek population sample, their accuracy was consistently over $82 \%$. The DFs based on the right-side measurements exhibited slightly better overall performance, although Function 15 yielded the best classification score (84.3\%) on the left-side measurements. Regarding the nine DFs produced from our sample, which correspond to previously published functions, in most of the cases, the equations based on the right-side measurements outperform their left-side counterparts. The only exceptions concern the Functions 5 and 7, which showed negligible improvement on the left side.

Table 7 summarizes the classification accuracy of the application of the previously reported DFs on the Greek sample. As expected, their discriminant capacity is reduced as compared to the classification accuracy of the respective DFs derived from the Greek sample. More specifically, the accuracy ranged from 63.78 to $83.84 \%$ when applied on the left-side measurements and from $68.11 \%$ to $83.84 \%$ when the right-side measurements were used. The highest sex discriminant capacity was observed with Function 3, which incorporated nine variables and reached $83.84 \%$ correct classification for both sides. The lowest correct classification accuracy was exhibited by Function 1, which correctly classified $63.79 \%$ and $68.11 \%$ of the Greek sample, when using the leftand the right-side measurements, respectively. Finally, it should be noted that the DF reported by Dong et al. (2015) could not be applied on our sample, since they omitted to report the DF's constant value in their paper.

\section{Discussion and conclusions}

In anthropometric studies, the determination of measurement error is essential (Ulijaszek and Lourie 1994). According to this study, all measurements exhibited an acceptable measurement error indicating high repeatability and precision, whereas their respective $\mathrm{R}$ coefficients demonstrated that all measurements may be regarded as reliable. These findings are in agreement with those reported by Toneva et al. (2016). Furthermore, most of the measurements are below the intraand inter-observer \%TEM thresholds of $1 \%$ and $1.5 \%$, respectively, which are usually considered acceptable for skillful anthropometrists (Perini et al. 2005). Despite that the photogrammetric $3 \mathrm{D}$ modeling of the mandibles was 
Table 3 Descriptive statistics for each measurement variable

\begin{tabular}{|c|c|c|c|c|c|c|}
\hline \multirow[t]{2}{*}{ Measurement } & \multicolumn{3}{|l|}{ Males } & \multicolumn{3}{|l|}{ Females } \\
\hline & Mean & Std. deviation & Shapiro-Wilk & Mean & Std. deviation & Shapiro-Wilk \\
\hline $\mathrm{BicBR}$ & 118.106 & 6.674 & 0.602 & 113.002 & 4.691 & 0.230 \\
\hline BigBR & 98.653 & 5.502 & 0.757 & 90.961 & 4.593 & 0.537 \\
\hline BicrBR & 94.753 & 4.243 & 0.582 & 90.456 & 5.448 & 0.083 \\
\hline SyH & 31.107 & 3.507 & 0.914 & 27.935 & 2.246 & 0.201 \\
\hline BimfBR & 45.318 & 2.230 & 0.871 & 43.547 & 2.259 & 0.750 \\
\hline SyBR & 20.084 & 1.759 & 0.395 & 19.251 & 1.239 & 0.107 \\
\hline RH-right & 65.968 & 4.608 & $0.200^{\mathrm{a}}$ & 59.624 & 3.842 & 0.538 \\
\hline MRH-right & 71.562 & 4.642 & 0.697 & 64.387 & 3.842 & 0.739 \\
\hline PRH-right & 58.109 & 6.944 & 0.907 & 52.429 & 5.038 & 0.606 \\
\hline $\mathrm{CH}$-right & 68.257 & 4.982 & 0.975 & 59.891 & 4.485 & 0.814 \\
\hline MaxRBR-right & 40.758 & 3.065 & 0.237 & 38.354 & 3.844 & 0.090 \\
\hline MinRBR-right & 31.446 & 2.877 & 0.232 & 30.138 & 2.697 & 0.531 \\
\hline NL-right & 34.537 & 3.094 & 0.001 & 32.730 & 3.472 & 0.214 \\
\hline CGL-right & 63.835 & 5.001 & 0.799 & 56.159 & 4.325 & 0.770 \\
\hline MaxBL-right & 84.172 & 4.740 & 0.268 & 79.383 & 4.087 & 0.766 \\
\hline BL-right & 80.940 & 4.511 & 0.277 & 75.870 & 3.877 & 0.882 \\
\hline MaxML-right & 124.716 & 5.181 & 0.286 & 116.618 & 4.542 & 0.881 \\
\hline RH-left & 66.233 & 4.196 & 0.141 & 60.281 & 3.892 & 0.566 \\
\hline MRH-left & 71.481 & 4.625 & 0.771 & 64.385 & 4.224 & 0.829 \\
\hline PRH-left & 57.917 & 6.554 & 0.845 & 52.749 & 5.141 & 0.365 \\
\hline $\mathrm{CH}$-left & 68.125 & 4.458 & 0.412 & 60.255 & 4.563 & 0.336 \\
\hline MaxRBR-left & 40.812 & 3.032 & 0.341 & 38.455 & 3.724 & 0.050 \\
\hline MinRBR-left & 31.461 & 2.633 & 0.399 & 30.473 & 2.396 & 0.771 \\
\hline NL-left & 34.563 & 3.294 & 0.380 & 33.143 & 3.626 & 0.486 \\
\hline CGL-left & 63.867 & 4.286 & 0.657 & 56.649 & 4.457 & 0.077 \\
\hline MaxBL-left & 83.343 & 4.507 & 0.211 & 78.557 & 4.449 & 0.203 \\
\hline BL-left & 80.188 & 4.389 & $0.200^{a}$ & 75.087 & 4.310 & 0.412 \\
\hline MaxML-left & 124.710 & 5.780 & 0.488 & 116.576 & 4.311 & 0.959 \\
\hline BilBR & 80.371 & 3.268 & 0.673 & 75.993 & 3.112 & 0.081 \\
\hline$M B$ & 83.984 & 2.834 & 0.346 & 80.665 & 3.499 & 0.553 \\
\hline BinBR & 95.934 & 4.236 & 0.889 & 92.168 & 4.260 & 0.650 \\
\hline Agn-go & 75.661 & 4.991 & 0.664 & 74.229 & 4.216 & 0.138 \\
\hline Agn-CO & 53.891 & 2.999 & 0.910 & 56.805 & 3.020 & 0.384 \\
\hline Agn-cdl & 57.626 & 3.778 & 0.764 & 59.438 & 3.104 & 0.679 \\
\hline
\end{tabular}

a normality checked with KS test

not part of the present study, the reported crossvalidated accuracy between digital and manual measurements, which was part of the digital documentation process, is smaller than the inter- and intraobserver absolute TEMs reported in the present study. Hence, the present results and DFs can be applied to either digital or manual measurements without any inter-method measurement error weakening their utility.
The aim of the present study has been twofold. We aimed to identify the mandibular measurements based on a modern Greek population sample that yield the highest sex discriminant capacity and use them to produce multivariate DFs that most successfully can estimate sex. Meanwhile, we investigated the performance of previously published DFs derived from different population samples. Population specificity is a long and well-established observation in osteometric studies also evident from our results (Giles 1964; 
Table 4 ANOVA and linear discriminant analysis for each measurement variable

\begin{tabular}{|c|c|c|c|c|c|c|}
\hline \multirow[t]{2}{*}{ Measurement } & \multirow{2}{*}{$\begin{array}{l}\text { Sample size } \\
\text { Total }(\hat{\jmath}-+)\end{array}$} & \multicolumn{2}{|l|}{ ANOVA } & \multicolumn{3}{|l|}{ Univariate DFAs } \\
\hline & & $\bar{F}$ & Sig. & Wilks' Lambda & Sig. & Cross-validated (\%) \\
\hline BicBR & $187(101-86)$ & $34.128^{a}$ & $<0.001$ & 0.850 & $<0.001$ & 65.8 \\
\hline BigBR & $194(105-89)$ & 55.614 & $<0.001$ & 0.775 & $<0.001$ & 73.2 \\
\hline BicrBR & $192(103-89)$ & 36.408 & $<0.001$ & 0.839 & $<0.001$ & 65.6 \\
\hline SyH & $105(58-47)$ & $25.357^{\mathrm{a}}$ & $<0.001$ & 0.817 & $<0.001$ & 72.4 \\
\hline BimfBR & $184(101-83)$ & 18.118 & $<0.001$ & 0.909 & $<0.001$ & 64.7 \\
\hline SyBR & $112(63-49)$ & $4.026^{\mathrm{a}}$ & 0.047 & 0.968 & 0.059 & 60.7 \\
\hline $\mathrm{RH}$-right & $193(105-88)$ & $143.997^{a}$ & $<0.001$ & 0.578 & $<0.001$ & 80.3 \\
\hline MRH-right & $194(105-89)$ & 130.603 & $<0.001$ & 0.595 & $<0.001$ & 78.4 \\
\hline PRH-right & 194 (105-89) & 54.279 & $<0.001$ & 0.780 & $<0.001$ & 69.1 \\
\hline $\mathrm{CH}$-right & $192(104-88)$ & 92.520 & $<0.001$ & 0.673 & $<0.001$ & 75.5 \\
\hline MaxRBR-right & $192(104-88)$ & 24.214 & $<0.001$ & 0.887 & $<0.001$ & 63.0 \\
\hline MinRBR-right & $194(105-89)$ & 6.251 & 0.013 & 0.968 & 0.013 & 58.8 \\
\hline NL-right & $191(103-88)$ & - & - & 0.928 & $<0.001$ & 59.7 \\
\hline CGL-right & 192 (103-89) & 101.686 & $<0.001$ & 0.651 & $<0.001$ & 77.6 \\
\hline MaxBL-right & $192(105-87)$ & 35.913 & $<0.001$ & 0.841 & $<0.001$ & 66.7 \\
\hline BL-right & $194(105-89)$ & 37.105 & $<0.001$ & 0.838 & $<0.001$ & 65.5 \\
\hline MaxML-right & $191(105-86)$ & 117.120 & $<0.001$ & 0.617 & $<0.001$ & 82.7 \\
\hline RH-left & $193(104-89)$ & $128.705^{\mathrm{a}}$ & $<0.001$ & 0.605 & $<0.001$ & 75.6 \\
\hline MRH-left & 193 (104-89) & 113.412 & $<0.001$ & 0.627 & $<0.001$ & 78.8 \\
\hline PRH-left & 193 (104-89) & 46.203 & $<0.001$ & 0.805 & $<0.001$ & 68.4 \\
\hline CH-left & $192(104-88)$ & 91.658 & $<0.001$ & 0.675 & $<0.001$ & 76.0 \\
\hline MaxRBR-left & $194(105-89)$ & 25.662 & $<0.001$ & 0.882 & $<0.001$ & 61.9 \\
\hline MinRBR-left & 194 (105-89) & 7.653 & 0.006 & 0.962 & 0.006 & 58.2 \\
\hline NL-left & 193 (104-89) & 10.675 & 0.001 & 0.947 & 0.001 & 57.5 \\
\hline CGL-left & 194 (105-89) & 99.576 & $<0.001$ & 0.658 & $<0.001$ & 77.8 \\
\hline MaxBL-left & $192(105-87)$ & 33.815 & $<0.001$ & 0.849 & $<0.001$ & 64.6 \\
\hline BL-left & 194 (105-89) & 32.626 & $<0.001$ & 0.855 & $<0.001$ & 64.4 \\
\hline MaxML-left & $191(104-87)$ & $120.559^{a}$ & $<0.001$ & 0.624 & $<0.001$ & 78.5 \\
\hline BilBR & 193 (104-89) & 76.144 & $<0.001$ & 0.715 & $<0.001$ & 72.5 \\
\hline $\mathrm{MB}$ & 189 (102-87) & 33.036 & $<0.001$ & 0.850 & $<0.001$ & 64.0 \\
\hline BinBR & $189(102-87)$ & 35.789 & $<0.001$ & 0.839 & $<0.001$ & 66.1 \\
\hline Agn-go & 194 (105-89) & 2.948 & 0.088 & 0.985 & 0.088 & 56.7 \\
\hline Agn-co & $192(103-89)$ & 23.503 & $<0.001$ & 0.890 & $<0.001$ & 64.6 \\
\hline Agn-cdl & $187(101-86)$ & 11.642 & 0.001 & 0.941 & 0.001 & 57.8 \\
\hline
\end{tabular}

asymptotically F-distributed values based on Welch ANOVA

İșcan and Steyn 1999; Franklin et al. 2007). Nevertheless, the rationale of our approach was not limited to a mere validation of population specificity but further aimed to identify particular morphometric traits that consistently yield high sex classification results among different population groups even though their expression patterns may vary among these groups.

Our findings regarding the most sex discriminant mandibular traits were consistent with earlier studies by
Franklin et al. (2006, 2008), who found that the coronoid height, the ramus height, and the maximum mandibular length univariately exhibited the most pronounced sexual dimorphism. Furthermore, the produced DF (Function 10, Table 5), when combining these measurements from the Greek population sample, yielded a crossvalidated accuracy of $84.1 \%$. Although the cranium and the pelvis provide much more reliable sex estimates (Oikonomopoulou et al. 2017; Bertsatos et al. 2018), our 
Table 5 Discriminant functions based on the right-side measurements

\begin{tabular}{|c|c|c|c|c|c|}
\hline \multirow[t]{2}{*}{ Equation } & \multirow{2}{*}{$\begin{array}{l}\text { Wilks' } \\
\text { Lambda }\end{array}$} & \multirow[t]{2}{*}{ Sig. } & \multirow{2}{*}{$\begin{array}{l}\text { Group centroids and sectioning } \\
\text { point }\end{array}$} & \multicolumn{2}{|c|}{ Correctly classified } \\
\hline & & & & Original & Cross-validated \\
\hline Function $1^{\mathrm{a}}$ & 0.571 & $<0.001$ & q-0.945, [-0.0795], ふ̋0.786 & $83.20 \%$ & $81.60 \%$ \\
\hline \multicolumn{6}{|c|}{$(B i c B R \times 0.022)+(B i g B R \times 0.063)+(\operatorname{MinRBR} \times-0.026)+(B L \times-0.043)+(M a x M L \times 0.183)-26.447$} \\
\hline Function $2^{\mathrm{b}}$ & 0.492 & $<0.001$ & q $-1.105,[-0.091], \partial^{\top} 0.923$ & $85.20 \%$ & $85.20 \%$ \\
\hline \multicolumn{6}{|c|}{$(\mathrm{BigBR} \times 0.052)+(\mathrm{CGL} \times 0.115)+(\mathrm{MaxML} \times 0.114)-25.567$} \\
\hline Function $3^{\mathrm{b}}$ & 0.381 & $<0.001$ & O+ $1.411,[-0.141], \delta 1.129$ & $89.90 \%$ & $84.80 \%$ \\
\hline \multicolumn{6}{|c|}{$\begin{array}{l}(B i c B R \times-0.037)+(B i g B R \times 0.103)+(B i c r B R \times 0.007)+(S y H \times 0.032)+(S y B R \times-0.041)+(R H \times-0.017)+(C G L \times 0.151)+ \\
(M a x B L \times-0.047)+(M a x M L \times 0.126)-25.838\end{array}$} \\
\hline Function $4^{\text {b }}$ & 0.481 & $<0.001$ & q- 1.131, [-0.0935], ठ̊0.944 & $85.70 \%$ & $85.70 \%$ \\
\hline \multicolumn{6}{|c|}{$(B i g B R \times 0.064)+(C G L \times 0.119)+(\operatorname{MaxBL} \times-0.063)+(\operatorname{MaxML} \times 0.139)-24.786$} \\
\hline Function $5^{c}$ & 0.532 & $<0.001$ & of $-1.015,[-0.078], \partial^{\top} 0.859$ & $82.30 \%$ & $81.80 \%$ \\
\hline \multicolumn{6}{|c|}{$(\mathrm{MRH} \times 0.214)+(\mathrm{PRH} \times-0.064)+(\mathrm{CH} \times 0.09)+(\mathrm{MaxRBR} \times 0.100)+(\operatorname{MinRBR} \times-0.124)-16.856$} \\
\hline Function $6^{c}$ & 0.633 & $<0.001$ & $q-0.824,[-0.0635], \partial^{\top} 0.697$ & $80.20 \%$ & $79.70 \%$ \\
\hline \multicolumn{6}{|c|}{$(\mathrm{CH} \times 0.180)+(\operatorname{MaxRBR} \times 0.137)+(\operatorname{MinRBR} \times-0.133)-12.807$} \\
\hline Function $7^{d}$ & 0.594 & $<0.001$ & 우 -0.894, [-0.0685], ふ̋0.757 & $77.10 \%$ & $77.10 \%$ \\
\hline \multicolumn{6}{|c|}{$(\mathrm{MRH} \times 0.220)+(\operatorname{MaxRBR} \times 0.029)-16.028$} \\
\hline Function $8^{d}$ & 0.585 & $<0.001$ & $+9-0.91,[-0.069], 300.772$ & $80.40 \%$ & $80.40 \%$ \\
\hline \multicolumn{6}{|c|}{$(M R H \times 0.247)+(\operatorname{MinRBR} \times-0.072)-14.495$} \\
\hline Function $9^{e}$ & 0.519 & $<0.001$ & q $-1.05,[-0.0885], \delta^{\top} 0.873$ & $85.90 \%$ & $84.90 \%$ \\
\hline \multicolumn{6}{|c|}{$(B i c B R \times 0.008)+(B i g B R \times 0.049)+(M R H \times 0.127)+(M a \times M L \times 0.087)-24.711$} \\
\hline Function $10^{f}$ & 0.498 & $<0.001$ & $q-1.105,[-0.101], \partial^{\top} 0.903$ & $84.10 \%$ & $84.10 \%$ \\
\hline \multicolumn{6}{|c|}{$(\mathrm{RH} \times 0.097)+(\mathrm{CH} \times 0.072)+(\mathrm{MaxML} \times 0.102)-22.935$} \\
\hline Function $11^{f}$ & 0.515 & $<0.001$ & ㅇ- $1.068,[-0.0975], 0 ̋ 0.873$ & $84.10 \%$ & $83.60 \%$ \\
\hline \multicolumn{6}{|c|}{$(\mathrm{MRH} \times 0.063)+(\mathrm{CH} \times 0.079)+(\mathrm{MaxML} \times 0.118)-23.516$} \\
\hline Function $12^{f}$ & 0.494 & $<0.001$ & P $-1.102,[-0.091], \delta^{\top} 0.92$ & $84.10 \%$ & $84.10 \%$ \\
\hline \multicolumn{6}{|c|}{$(\mathrm{RH} \times 0.081)+(\mathrm{CGL} \times 0.086)+(\mathrm{MaxML} \times 0.108)-23.085$} \\
\hline Function $13^{f}$ & 0.498 & $<0.001$ & $q-1.093,[-0.0905], \delta^{1} 0.912$ & $84.10 \%$ & $83.10 \%$ \\
\hline$(\mathrm{MRH} \times 0 . \mathrm{C}$ & $0.096)+($ & 11) -23 & & & \\
\hline
\end{tabular}

${ }^{\mathrm{a}}$ Function based on Steyn and İscan (1998)

${ }^{\mathrm{b}}$ Function based on Franklin et al. (2008)

${ }^{\mathrm{C}}$ Function based on Saini et al. (2011)

${ }^{\mathrm{d}}$ Function based on Lin et al. (2014)

Function based on Dong et al. (2015)

${ }^{\mathrm{f}} \mathrm{A}$ combination of the five variables with the highest univariate discriminating capacity. Their corresponding DFA analysis using the stepwise method yielded identical function and accuracy

results verify that the mandible can be useful for estimating sex in a forensic context, when cranial and pelvic elements are missing or deteriorated.

Franklin and colleagues in 2008 studied 225 individuals (120 male; 105 female) from five local populations of indigenous South Africans, in order to produce a series of mandibular metric standards for sex estimation, which resulted in Functions 2, 3, and 4 (see Table 7). The corresponding DFs based on the Greek sample (Tables 5 and 6) yielded the highest sex discriminant scores observed in the present study ranging from 84.3 to 85.7\%. More specifically, Function 3, which includes nine mandibular measurements, yielded similar classification accuracy on our sample (84.8\%) with that reported by Franklin and colleagues on their population sample (84\%). Furthermore, applying the original DF (Franklin et al. 2008) on the Greek population sample also resulted to similar accuracy (83.84\%). However, the accuracy of Functions 2 and 4, which utilize three and four mandibular measurements, respectively, was higher for the DFs derived from the Greek population (Function 2: right side $85.2 \%$, left side $84.3 \%$; Function 4 : right side $85.7 \%$, left side $84.8 \%$ ) as opposed to their counterparts derived from the indigenous South African population (Function 2: 81.8\%; Function 4: 82.7\%). Additionally, applying the original DFs on the Greek population sample 
Table 6 Discriminant functions based on the left-side measurements

\begin{tabular}{|c|c|c|c|c|c|}
\hline \multirow[t]{2}{*}{ Equation } & \multirow{2}{*}{$\begin{array}{l}\text { Wilks' } \\
\text { Lambda }\end{array}$} & \multirow[t]{2}{*}{ Sig. } & \multirow{2}{*}{$\begin{array}{l}\text { Group centroids and sectioning } \\
\text { point }\end{array}$} & \multicolumn{2}{|c|}{ Correctly classified } \\
\hline & & & & Original & Cross-validated \\
\hline Function $1^{\text {a }}$ & 0.587 & $<0.001$ & q-0.915, [-0.077], ふ̋0.761 & $83.20 \%$ & $81.60 \%$ \\
\hline \multicolumn{6}{|c|}{$(B i c B R \times 0.028)+(B i g B R \times 0.065)+(\operatorname{MinRBR} \times-0.014)+(B L \times-0.042)+(M a x M L \times 0.174)-26.748$} \\
\hline Function $2^{\mathrm{b}}$ & 0.506 & $<0.001$ & 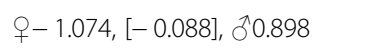 & $84.30 \%$ & $84.30 \%$ \\
\hline \multicolumn{6}{|c|}{$(B i g B R \times 0.056)+(C G L \times 0.117)+($ MaxML $\times 0.109)-25.455$} \\
\hline Function $3^{b}$ & 0.399 & $<0.001$ & of $-1.36,[-0.136], 031.088$ & $89.90 \%$ & $84.80 \%$ \\
\hline \multicolumn{6}{|c|}{$\begin{array}{l}(B i c B R \times-0.017)+(B i g B R \times 0.101)+(B i c r B R \times 0.002)+(S y H \times 0.024)+(S y B R \times-0.020)+(R H \times-0.010)+(C G L \times 0.154)+ \\
(M a x B L \times-0.034)+(M a x M L \times 0.099)-26.007\end{array}$} \\
\hline Function $4^{\mathrm{b}}$ & 0.497 & $<0.001$ & O+-1.095, [-0.0895], ổ0.916 & $85.30 \%$ & $84.80 \%$ \\
\hline \multicolumn{6}{|c|}{$(\mathrm{BigBR} \times 0.069)+(\mathrm{CGL} \times 0.122)+(\mathrm{MaxBL} \times-0.056)+(\mathrm{MaxML} \times 0.128)-24.741$} \\
\hline Function $5^{c}$ & 0.546 & $<0.001$ & q $-0.981,[-0.0715], o^{\top} 0.838$ & $83.80 \%$ & $82.20 \%$ \\
\hline \multicolumn{6}{|c|}{$(\mathrm{MRH} \times 0.179)+(\mathrm{PRH} \times-0.047)+(\mathrm{CH} \times 0.098)+(\mathrm{MaxRBR} \times 0.123)+(\mathrm{MinRBR} \times-0.166)-15.675$} \\
\hline Function $6^{c}$ & 0.619 & $<0.001$ & O. $-0.848,[-0.065], \delta^{\wedge} 0.718$ & $79.20 \%$ & $78.60 \%$ \\
\hline \multicolumn{6}{|c|}{$(\mathrm{CH} \times 0.182)+(\operatorname{MaxRBR} \times 0.169)+(\operatorname{MinRBR} \times-0.159)-13.474$} \\
\hline Function $7^{d}$ & 0.626 & $<0.001$ & $q-0.832,[-0.06], \delta^{\top} 0.712$ & $77.70 \%$ & $77.20 \%$ \\
\hline \multicolumn{6}{|c|}{$(\mathrm{MRH} \times 0.211)+(\mathrm{MaxRBR} \times 0.027)-15.299$} \\
\hline Function $8^{\mathrm{d}}$ & 0.61 & $<0.001$ & $q-0.86,[-0.062], \delta^{\wedge} 0.736$ & $80.30 \%$ & $80.30 \%$ \\
\hline \multicolumn{6}{|c|}{$(M R H \times 0.245)+(\operatorname{MinRBR} \times-0.107)-13.339$} \\
\hline Function $9^{e}$ & 0.545 & $<0.001$ & q $-0.997,[-0.084], \precsim 30.829$ & $84.30 \%$ & $82.70 \%$ \\
\hline \multicolumn{6}{|c|}{$(B i c B R \times 0.014)+(B i g B R \times 0.055)+(M R H \times 0.116)+(M a \times M L \times 0.082)-24.524$} \\
\hline Function $10^{f}$ & 0.525 & $<0.001$ & of $-1.029,[-0.0795]$, Ĵ0.87 & $83.20 \%$ & $82.10 \%$ \\
\hline \multicolumn{6}{|c|}{$(\mathrm{RH} \times 0.086)+(\mathrm{CH} \times 0.079)+(\mathrm{MaxML} \times 0.100)-22.525$} \\
\hline Function $11^{9}$ & 0.538 & $<0.001$ & o $-1.003,[-0.078], \widehat{\partial} 0.847$ & $83.70 \%$ & $83.20 \%$ \\
\hline \multicolumn{6}{|c|}{$(\mathrm{MRH} \times 0.045)+(\mathrm{CH} \times 0.088)+(\mathrm{MaxML} \times 0.118)-22.900$} \\
\hline Function $12^{\text {h }}$ & 0.542 & $<0.001$ & of $-0.995,[-0.0775]$, ô0.84 & $84.20 \%$ & $83.20 \%$ \\
\hline \multicolumn{6}{|c|}{$(\mathrm{CH} \times 0.110)+(\mathrm{MaxML} \times 0.138)-23.604$} \\
\hline Function $13^{f}$ & 0.518 & $<0.001$ & q $-1.05,[-0.086], \delta^{2} 0.878$ & $83.20 \%$ & $82.70 \%$ \\
\hline \multicolumn{6}{|c|}{$(\mathrm{RH} \times 0.066)+(\mathrm{CGL} \times 0.095)+(\mathrm{MaxML} \times 0.109)-22.949$} \\
\hline Function $14^{9}$ & 0.523 & $<0.001$ & o $-1.039,[-0.085], 300.869$ & $84.30 \%$ & $83.80 \%$ \\
\hline \multicolumn{6}{|c|}{$(\mathrm{MRH} \times 0.041)+(\mathrm{CGL} \times 0.104)+(\mathrm{MaxML} \times 0.118)-23.137$} \\
\hline Function $15^{i}$ & 0.527 & $<0.001$ & $q-1.031,[-0.0845], o^{\wedge} 0.862$ & $84.80 \%$ & $84.30 \%$ \\
\hline$(C G L \times 0.123$ & $\times 0.137)$ & & & & \\
\hline
\end{tabular}

${ }^{\mathrm{a}}$ Function based on Steyn and İscan (1998)

${ }^{\mathrm{b}}$ Function based on Franklin et al. (2008)

${ }^{\mathrm{C}}$ Function based on Saini et al. (2011)

${ }^{d}$ Function based on Lin et al. (2014)

eFunction based on Dong et al. (2015)

${ }^{\mathrm{f}} \mathrm{A}$ combination of the five variables with the highest univariate discriminating capacity. Their corresponding DFA analysis using the stepwise method yielded identical function and accuracy

${ }^{9} \mathrm{~A}$ combination of the five variables with the highest univariate discriminating capacity

${ }^{\mathrm{h}}$ The outcome of the stepwise DFA analysis using the variables of function 11

'The outcome of the stepwise DFA analysis using the variables of function 14

yielded even lower classification scores (see Table 7). Despite that Functions 2 and 4 resulted in differential performance between the two distinct population groups, which can be attributed to population specificity, the overall performance of these three functions implies some merit to the proposed metric standards by Franklin et al. (2008).
Steyn and İșcan in 1998 evaluated sexual dimorphism in the cranium and the mandible of South African Whites and developed osteometric standards to determine sex. They studied 91 South African Whites (44 males, 47 females) from cadaver collections housed at the Universities of Pretoria and Witwatersrand (Dart Collection). Although comparing their results to our 
Table 7 The accuracy of other researchers' equations as well as their accuracy when applied on the Greek population sample

\begin{tabular}{|c|c|c|c|c|c|c|}
\hline \multirow{2}{*}{$\begin{array}{l}\text { Date } \\
1998\end{array}$} & \multirow{2}{*}{$\begin{array}{l}\text { Authors } \\
\text { Steyn and Iscan }\end{array}$} & \multirow{2}{*}{$\begin{array}{l}\text { Population } \\
\text { South African Whites }\end{array}$} & \multirow{2}{*}{$\begin{array}{l}\text { DF } \\
\text { Function } 1\end{array}$} & \multirow{2}{*}{$\begin{array}{l}\text { DF's performance on reference } \\
\text { population } \\
81.5 \%\end{array}$} & \multicolumn{2}{|c|}{$\begin{array}{l}\text { DF's performance applied on the } \\
\text { Greek sample }\end{array}$} \\
\hline & & & & & Left side: & $63.78 \%$ \\
\hline & & & & & Right side: & $68.11 \%$ \\
\hline \multirow[t]{2}{*}{2008} & Franklin et al. & South African Blacks & Function 2 & $81.8 \%$ & Left side: & $72.77 \%$ \\
\hline & & & & & Right side: & $74.60 \%$ \\
\hline \multirow[t]{2}{*}{2008} & Franklin et al. & South African Blacks & Function 3 & $84.0 \%$ & Left side: & $83.84 \%$ \\
\hline & & & & & Right side: & $83.84 \%$ \\
\hline \multirow[t]{2}{*}{2008} & Franklin et al. & South African Blacks & Function 4 & $82.7 \%$ & Left side: & $78.53 \%$ \\
\hline & & & & & Right side: & $77.78 \%$ \\
\hline \multirow[t]{2}{*}{2011} & Saini et al. & Indian & Function 5 & $80.2 \%$ & Left side: & $65.45 \%$ \\
\hline & & & & & Right side: & $68.75 \%$ \\
\hline \multirow[t]{2}{*}{2011} & Saini et al. & Indian & Function 6 & $80.2 \%$ & Left side: & $75.00 \%$ \\
\hline & & & & & Right side: & $71.88 \%$ \\
\hline \multirow[t]{2}{*}{2014} & Lin et al. & Korean & Function 7 & $80.8 \%$ & Left side: & $67.36 \%$ \\
\hline & & & & & Right side: & $68.75 \%$ \\
\hline \multirow[t]{2}{*}{2014} & Lin et al. & Korean & Function 8 & $80.0 \%$ & Left side: & $68.84 \%$ \\
\hline & & & & & Right side: & $69.59 \%$ \\
\hline
\end{tabular}

corresponding DF results (Function 1) revealed similar classification accuracy $(\sim 81.5 \%)$, applying the original DF (Steyn and İscan 1998) on the modern Greek population sample exhibited much lower accuracy (left side: $63.78 \%$; right side: $68.11 \%$ ). The same pattern was observed on the rest of the comparisons between different population samples. The corresponding DFs produced similar classification accuracy between their respective reference population samples, but applying the original DFs (from other population samples) on the Greek sample resulted in significantly reduced accuracy.

More specifically, Saini et al. (2011), working on 116 dry adult mandibles of a Northern Indian population sample from the Department of Forensic Medicine in India, reported classification accuracy of $80.2 \%$ for both Functions 5 and 6, which on our sample yielded approximately $82 \%$ and $79 \%$, respectively, with small deviations on each side. Lin et al. (2014) produced their DFs from cranial CT scans of 120 males and 120 females from Seoul St. Mary's Hospital. Despite most of their reported DFs were based on different set of measurements than these utilized in the present study, which restricted a direct comparison with their most accurate DFs in terms of correct sex classification, the available comparisons showed similar classification score for Function 7 (77.2\% on Greek sample; $80.8 \%$ on Korean sample) and identical accuracy for Function 8 (80.4\%). Similarly, the DF reported by Dong and colleagues based on a contemporary Han Chinese population sample yielded $83.3 \%$ classification accuracy (Dong et al. 2015), whereas the corresponding DF from the Greek sample produced
82.7\% and $84.9 \%$ cross-validated classification scores for the left- and right-side measurements, respectively.

The present study produced a number of suitable DFs based on mandibular measurements that can be used for sexing unidentified individuals assumed to belong to the modern Greek population. Apart from verifying the fact that most often the morphometric DFs based on human bones exhibit population specificity, hence the need for studies on different population samples, the comparative part of this work also revealed some interesting aspects. The observation that the same combinations of measurements yield the same sex discriminant capacity between different population samples, despite their respective DFs being population specific, implies that the magnitude of expression of sexual dimorphism is similar on certain mandibular morphometric traits and shared across different populations, although their expression may follow different patterns in each population group. Regarding the identical results of Function 3 (Franklin et al. 2008) and especially the identical classification accuracy when applying the DF derived from indigenous South Africans on the Greek population, we cannot conclude whether this observation is a mere statistical coincidence between the two reference samples or the result of both population groups sharing similar environmental and developmental factors that led to similar expression of sexual dimorphism in their mandibles. Further work is necessary to this end, and studies on shared datasets comprising diverse population samples may expand our insight on this matter and provide more reliable sex discriminant tools for the forensic practice. 


\section{Abbreviations}

DF: Discriminant function; DFA: Discriminant function analysis; TEM: Technical Error Measurement

\section{Acknowledgements}

Not applicable.

\section{Funding}

This research did not receive any grant from funding agencies in the public, commercial, or not-for-profit sectors.

\section{Availability of data and materials}

Please contact author for data requests.

\section{Declarations}

The authors declare that this manuscript is original, has not been published before, and is not currently being considered for publication elsewhere.

\section{Authors' contributions}

$A B$ contributed to the data collection, statistical analysis, and manuscript preparation. KA contributed to the data collection and manuscript preparation. M-EC contributed to the experimental design, statistical analysis, and manuscript preparation. All authors have read and approved the final article.

\section{Ethics approval and consent to participate} Not applicable.

\section{Consent for publication}

Not applicable.

\section{Competing interests}

The authors declare that they have no competing interests.

\section{Publisher's Note}

Springer Nature remains neutral with regard to jurisdictional claims in published maps and institutional affiliations.

\section{Received: 20 November 2018 Accepted: 15 May 2019} Published online: 24 May 2019

\section{References}

Bejdová Š, Krajíček V, Velemínská J, Horák M, Velemínský P (2013) Changes in the sexual dimorphism of the human mandible during the last 1200 years in Central Europe. HOMO. 64(6):437-453. https://doi.org/10.1016/j. jchb.2013.05.003

Bertsatos A, Chovalopoulou M-E (2017) Secular change in adult stature of modern Greeks. Am J Hum Biol. https://doi.org/10.1002/ajhb.23077

Bertsatos A, Papageorgopoulou C, Valakos E, Chovalopoulou M-E (2018) Investigating the sex-related geometric variation of the human cranium. Int J Legal Med 132(5):1505-1514. https://doi.org/10.1007/s00414-018-1790-z

Bidmos MA, Gibbon VE, Štrkalj G (2010) Recent advances in sex identification of human skeletal remains in South Africa. S Afr J Sci. https://doi.org/10.4102/ sajs.v106i11/12.238

Byers SN (2016) Introduction to forensic anthropology. Routledge, London

Carvalho SP, Brito LM, Paiva LA, Bicudo LA, Crosato EM, Oliveira RN (2013) Validation of a physical anthropology methodology using mandibles for gender estimation in a Brazilian population. J Appl Oral Sci. https://doi.org/ 10.1590/1678-775720130022

Cignoni P, Corsini M, Ranzuglia G (2008) MeshLab: an open-source 3D mesh processing system. ERCIM News 73:45-46

Coquerelle M, Bookstein FL, Braga J, Halazonetis DJ, Weber GW, Mitteroecker P (2011) Sexual dimorphism of the human mandible and its association with dental development. Am J Phys Anthropol. https://doi.org/10.1002/ajpa. 21485

Dayal M, Spocter M, Bidmos M (2008) An assessment of sex using the skull of black South Africans by discriminant function analysis. HOMO. 59(3):209-221. https://doi.org/10.1016/j.jchb.2007.01.001

Dixon SJ, Brereton RG (2009) Comparison of performance of five common classifiers represented as boundary methods: Euclidean distance to centroids, linear discriminant analysis, quadratic discriminant analysis, learning vector quantization and support vector machines, as dependent on data structure Chemom Intell Lab Syst. https://doi.org/10.1016/j.chemolab.2008.07.010

Dong H, Deng M, Wang W, Zhang J, Mu J, Zhu G (2015) Sexual dimorphism of the mandible in a contemporary Chinese Han population. Forensic Sci Int. https://doi.org/10.1016/j.forsciint.2015.06.010

Eaton JW, Bateman D, Hausberg S, Wehbring R (2016) GNU Octave version 4.2.0 manual: a high-level interactive language for numerical computations. https://octave.org/doc/interpreter/

Eliopoulos C, Lagia A, Manolis SK (2007) A modern, documented human skeletal collection from Greece. HOMO. https://doi.org/10.1016/j.jchb.2006.10.003

France DL (1998) Observational and metric analysis of sex in the skeleton. In: Reichs KJ (ed) Forensic osteology: advances in the identification of human remains. Charles C Thomas Publisher, Springfield, pp 163-186

Franklin D, Freedman L, Milne N (2005) Sexual dimorphism and discriminant function sexing in indigenous South African crania. HOMO. https://doi.org/ 10.1016/j.jchb.2004.08.001

Franklin D, O'Higgins P, Oxnard CE, Dadour I (2008) Discriminant function sexing of the mandible of Indigenous South Africans. Forensic Sci Int. https://doi. org/10.1016/j.forsciint.2008.03.014

Franklin D, O'Higgins P, Oxnard CE, Dadour I (2006) Determination of sex in South African Blacks by discriminant function analysis of mandibular linear dimensions: a preliminary investigation using the Zulu local population. Forensic Sci Med Pathol. https://doi.org/10.1385/fsmp:2:4:263

Franklin D, O'Higgins P, Oxnard CE, Dadour I (2007) Sexual dimorphism and population variation in the adult mandible. Forensic applications of geometric morphometrics. Forensic Sci Med Pathol. https://doi.org/10.1385/ fsmp:2:4:263

Giles E (1964) Sex determination by discriminant function analysis of the mandible. Am J Phys Anthropol. https://doi.org/10.1002/ajpa.1330220212

Hu KS, Koh KS, Han SH, Shin KJ, Kim HJ (2006) Sex determination using nonmetric characteristics of the mandible in Koreans. J Forensic Sci. https:// doi.org/10.1111/j.1556-4029.2006.00270.x

İşcan MY, Steyn M (1999) Craniometric determination of population affinity in South Africans. Int J Legal Med. https://doi.org/10.1007/s004140050208

Kano T, Oritani S, Michiue T, Ishikawa T, Hishmat AM, Sogawa N et al (2015) Postmortem CT morphometry with a proposal of novel parameters for sex discrimination of the mandible using Japanese adult data. Leg Med (Tokyo). https://doi.org/10.1016/j.legalmed.2014.12.009

Krishan K, Chatterjee PM, Kanchan T, Kaur S, Baryah N, Singh R (2016) A review of sex estimation techniques during examination of skeletal remains in forensic anthropology casework. Forensic Sci Int. https://doi.org/10.1016/j.forsciint. 2016.02.007

Lin C, Jiao B, Liu S, Guan F, Chung N, Han S et al (2014) Sex determination from the mandibular ramus flexure of Koreans by discrimination function analysis using three-dimensional mandible models. Forensic Sci Int. https://doi.org/ 10.1016/j.forsciint.2013.12.015

Lopez-Capp TT, Rynn C, Wilkinson C, De Paiva LA, Michel-Crosato E, Biazevic MG (2017) Discriminant analysis of mandibular measurements for the estimation of sex in a modern Brazilian sample. Int J Legal Med. https://doi.org/10.1007/ s00414-017-1681-8

Loth SR, Henneberg M (2001) Sexually dimorphic mandibular morphology in the first few years of life. Am J Phys Anthropol. https://doi.org/10.1002/ajpa.1067

Ogawa Y, Imaizumi K, Miyasaka S, Yoshino M (2013) Discriminant functions for sex estimation of modern Japanese skulls. J Forensic Legal Med. https://doi. org/10.1016/j.jflm.2012.09.023

Oikonomopoulou EK, Valakos E, Nikita E (2017) Population-specificity of sexual dimorphism in cranial and pelvic traits: evaluation of existing and proposal of new functions for sex assessment in a Greek assemblage. Int J Legal Med. https://doi.org/10.1007/s00414-017-1655-x

Passalacqua NV, Zhang Z, Pierce SJ (2013) Sex determination of human skeletal populations using latent profile analysis. Am J Phys Anthropol. https://doi. org/10.1002/ajpa.22295

Perini TA, de Oliveira GL, Ornellas JS, de Oliveira FP (2005) Technical error measurement in anthropometry. Rev Bras Med Esporte. https://doi.org/10. 1590/S1517-86922005000100009

Saini V, Srivastava R, Shamal SN, Singh T, Pandey AK, Tripathi SK (2011) Sex determination using mandibular ramus flexure: a preliminary study on Indian population. J Forensic Legal Med. https://doi.org/10.1016/j.jflm.2011.02.014

Scheuer $L$ (2002) A blind test of mandibular morphology for sexing mandibles in the first few years of life. Am J Phys Anthropol. https://doi.org/10.1002/ajpa. 10098 
Schutkowski H (1993) Sex determination of infant and juvenile skeletons: I. Morphognostic features. Am J Phys Anthropol. https://doi.org/10.1002/ajpa. 1330900206

Sharma M, Gorea R, Gorea A, Abuderman A (2016) A morphometric study of the human mandible in the Indian population for sex determination. Egypt J Forensic Sci. https://doi.org/10.1016/.j.jfs.2015.01.002

Steyn M, Işcan M (1998) Sexual dimorphism in the crania and mandibles of South African whites. Forensic Sci Int. https://doi.org/10.1016/s03790738(98)00120-0

Toneva DS, Nikolova S, Georgiev I, Tchorbadjieff A (2016) Intra- and interobserver measurement error of linear measurements on threedimensional computed tomography models of dry mandibles. Acta morphologica et anthropologica 23

Ubelaker DH, DeGaglia CM (2017) Population variation in skeletal sexual dimorphism. Forensic Sci Int. https://doi.org/10.1016/j.forsciint.2017.06.012

Ulijaszek SJ, Lourie JA (1994) Intra- and inter-observer error in anthropometric measurement. In: Ulijaszek SJ, Mascie-Taylor CGN (eds) Anthropometry: the individual and the population. University Press, Cambridge

\section{Submit your manuscript to a SpringerOpen ${ }^{\circ}$ journal and benefit from:}

- Convenient online submission

- Rigorous peer review

- Open access: articles freely available online

High visibility within the field

- Retaining the copyright to your article

Submit your next manuscript at $\boldsymbol{\nabla}$ springeropen.com 